Article

\title{
Design and Performance Prediction of a Dual-Band Coupled-Fed Dipole Array Antenna for PCL Systems in the VHF Band
}

\author{
Sungsik Wang ${ }^{1} \mathbb{D}$, Hongsuk Shim ${ }^{2}$ and Hosung Choo ${ }^{1, * \mathbb{D}}$ \\ 1 School of Electronic and Electrical Engineering, Hongik University, Seoul 04066, Korea; kingwss@gmail.com \\ 2 Hanwha Systems Co. Ltd., Seongnam City, Gyeonggi-Do 13524, Korea; hongsuk.shim@hanwha.com \\ * Correspondence: hschoo@hongik.ac.kr
}

Received: 4 February 2020; Accepted: 2 March 2020; Published: 6 March 2020

check for updates

Featured Application: This article is related to passive radars using public broadcast signals in the VHF band.

\begin{abstract}
This article proposes the design of a dual-band coupled-fed dipole antenna for passive coherent location (PCL) systems in the very high frequency (VHF) band. The proposed indirect coupled feed mechanism, which is often employed in microstrip patch antennas, is first applied to VHF band dipole elements for dual-band matching. To confirm the effectiveness of the proposed design, we fabricate the coupled-fed dipole element and measure antenna characteristics, such as the voltage standing wave ratio (VSWR) and the antenna gain. The proposed antenna element is then applied to an eight-element circular array to form the reference and surveillance beams for PCL systems. Finally, the target location is estimated by constructing amplitude-range doppler (ARD) maps for one frequency modulation (FM) and two terrain digital multimedia broadcasting (T-DMB) illuminators in the Seoul-Gyunggi urban area. The results confirm that the proposed element is suitable for dual-band PCL systems in the VHF band compared to a conventional dipole antenna.
\end{abstract}

Keywords: VHF; FM; dipole antenna; PCL; passive radar; coupled feed; dual-band

\section{Introduction}

In recent years, there has been ongoing development of aircraft with low-probability-of-intercept (LPI) capabilities, which are difficult to track using conventional radar systems. To counter these technologies, passive coherent location (PCL) radars using commercial low-frequency broadcast signals, such as frequency modulation (FM) radio [1,2], digital TV [3-6], analog TV [7], satellites [8,9], and mobile communications [10], have been studied extensively. In particular, PCL radars using low-frequency bands, including the very high frequency (VHF) band of FM broadband signals, can effectively counter long-range targets with radar absorbing material (RAM) or radar absorbing structure (RAS). In addition, PCL radars can dramatically reduce system hardware costs, effectively conceal the viewing position, and precisely estimate the target location with multi-static receivers, by using external illuminating sources often referred to as "illuminators of opportunity" [11]. In general, an appropriate number of illuminators is required to precisely pinpoint targets in the multi-static receiver PCL system [11]. However, as FM stations cannot cover all regions, additional commercial stations can also be utilized, such as terrain digital multimedia broadcasting (T-DMB, 174 216 MHz), which is similar to European digital audio broadcasting (DAB) communications. In order to extend PCL system performance from FM to T-DMB bands, it is necessary to improve individual antenna characteristics for both the FM band and the T-DMB band. Achieving this multi-band performance at low frequencies has been considered technically challenging. 
In this paper, we propose a novel design of an array antenna element that can achieve multi-frequency band operation by applying a coupled-fed technique to a dipole antenna. This coupled-fed technique, often used for broadband matching characteristics of microstrip patch antennas [12-14], is first applied to the design of the multi-band dipole antenna for PCL systems. The antenna element comprises an internal dipole and an external coupled-fed dipole. These internal and external dipoles are tightly attached to the housing structure, which includes the circuit board of a balun. Using the coupled-fed structure, the two resonances are appropriately controlled to achieve FM and T-DMB dual-band matching characteristics. To confirm the effectiveness of the proposed design, we fabricate the coupled-fed dipole element and measure antenna characteristics, such as the voltage standing wave ratio (VSWR) and the antenna gain. The proposed antenna element is then applied to an eight-element circular array to form the reference and surveillance beams in the T-DMB band. Finally, the target location is estimated by constructing amplitude-range doppler (ARD) maps for one FM and two T-DMB illuminators in the Seoul-Gyunggi urban area.

\section{Multi-Static Receiver PCL System}

Figure 1 shows elliptical trajectories for location estimation using the multi-static PCL system when three illuminators with one receiver are used for a single target. In Figure 1, the distance from the illuminator to the target is $R_{1}$, while the distance from the target to the receiver is $R_{2}$. The elliptical trajectory then comprises $R_{1}+R_{2}$, indicating the potential location of the target. If multiple ellipses are created by two or more illuminators, the point at which they intersect is the target's possible location. However, there exist "Ghost" points at the intersections that are not the correct location, and thus at least three illuminators are needed to accurately estimate the target position in the multi-static PCL system [11].

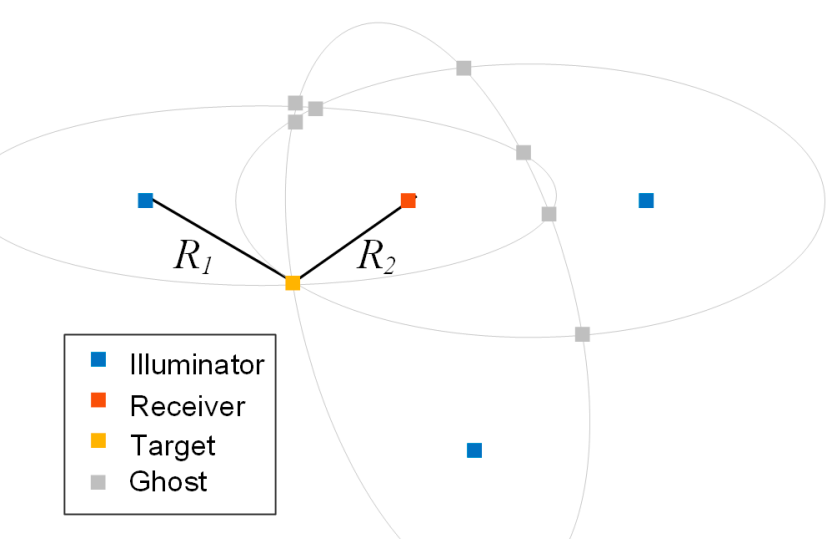

Figure 1. Elliptic trajectories corresponding to the multi-static passive coherent location (PCL) system (3 illuminators, 1 target, and 1 receiver).

Figure 2 illustrates the FM and T-DMB broadcast stations in the Seoul-Gyunggi urban area and the potential coverage region for the multi-static PCL system when those stations are used as illuminators. There are two FM stations, sixteen T-DMB stations, and two stations transmitting both FM and T-DMB. Assuming a maximum reception distance of about $100 \mathrm{~km}$ for typical FM and DMB broadcasts [11,15], the black, green, and purple circles represent the radius of $100 \mathrm{~km}$ within which the PCL system can estimate the target position using those FM stations. The overlapping area colored in yellow is the region of potential coverage by the PCL system where all three FM station signals can be used. Note that the south area of Seoul-Gyunggi cannot be covered by FM stations alone. If additional south T-DMB broadcast stations are added to the multi-static PCL system in this outer area, the PCL system's coverage can be extended to the entire urban area of Seoul-Gyunggi. 


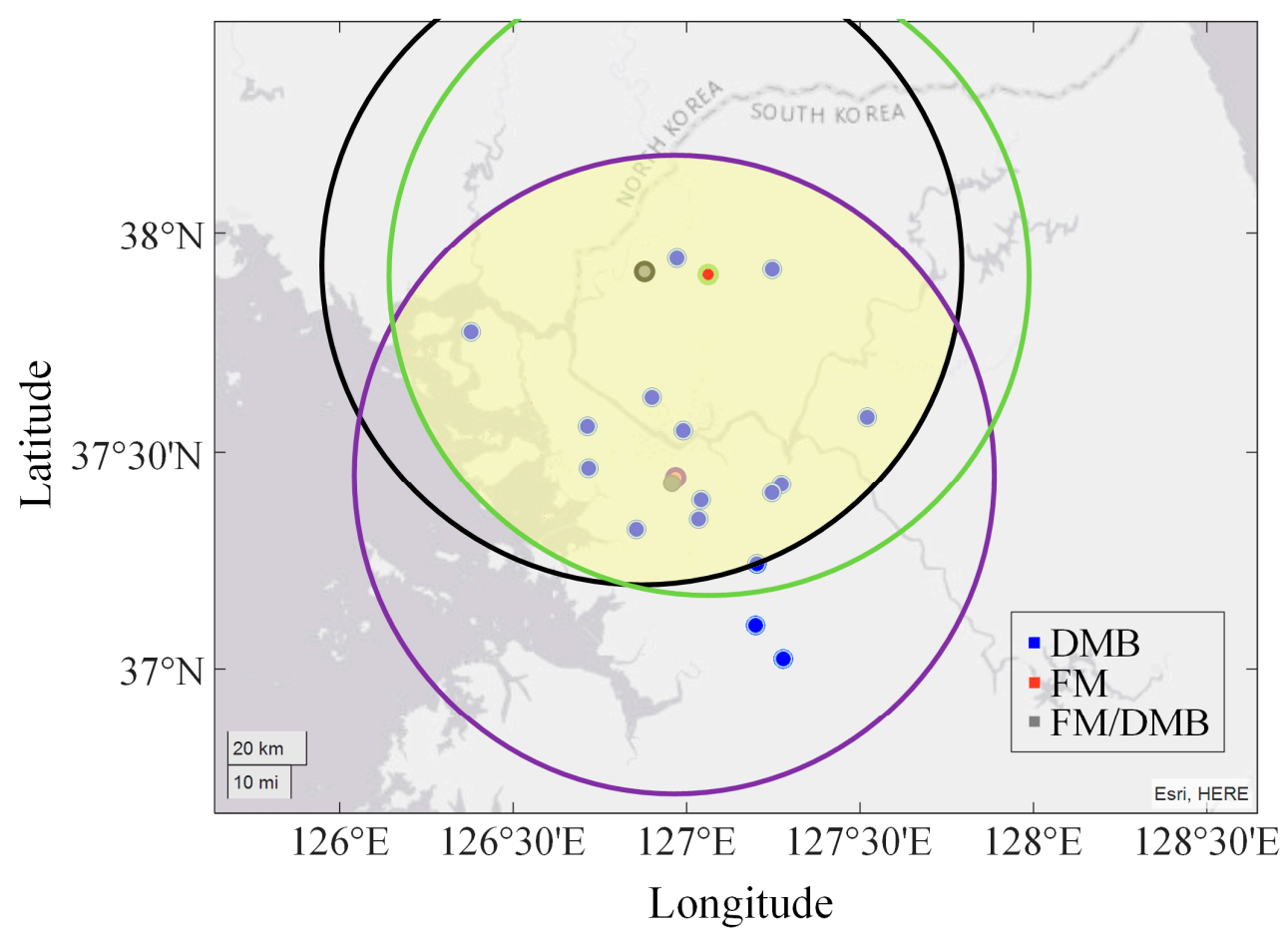

Figure 2. Frequency modulation (FM) and terrain digital multimedia broadcasting (T-DMB) broadcast stations with potential coverage area in the Seoul-Gyunggi urban area.

\section{Design of the Dual-Band Coupled-Fed Dipole Antenna}

Figure 3 shows the proposed dual-band dipole antenna with an electromagnetically coupled-fed structure. The antenna comprises internal and external dipoles with lengths $H_{\text {out }}$ and $H_{\text {in }}$ respectively, of which the values independently determine each resonance frequency. The internal dipole is fed directly by the circuit board with the balun, and the external and internal dipoles are electromagnetically coupled to achieve the additional T-DMB band matching characteristics. This coupled-fed mechanism, which has been employed in various broadband microstrip patch antennas [12-14], is first applied to the design of dual-band dipole antennas for the VHF frequency band. The coupled-fed mechanism used for the dipole element can achieve the dual-band matching characteristics, which can improve the illuminator of opportunity for PCL systems. The radius of the internal and external dipole radiators is denoted by $R_{\text {in }}$ and $R_{\text {out }}$, respectively. The separation gap between the internal and external dipoles is $S_{d 1}$. The optimal design parameters of the proposed antenna were derived using the FEKO electromagnetic simulator [16] in conjunction with a genetic algorithm [17], and they are listed in Table 1. Photographs of the proposed coupled-fed dipole antenna and the circuit board with the embedded balun are presented in Figure $3 \mathrm{~b}$. The two ports of the internal dipole inside the external dipole are firmly attached to the housing by screw-type connectors.

Table 1. Design parameters of the proposed antenna.

\begin{tabular}{cc}
\hline Parameters & Values \\
\hline$H_{\text {out }}$ & $460 \mathrm{~mm}$ \\
\hline$H_{\text {in }}$ & $670 \mathrm{~mm}$ \\
\hline$R_{\text {out }}$ & $62.5 \mathrm{~mm}$ \\
\hline$R_{\text {in }}$ & $15 \mathrm{~mm}$ \\
\hline$S_{d 1}$ & $47.5 \mathrm{~mm}$ \\
\hline$S_{d 2}$ & $1.6 \mathrm{~mm}$ \\
\hline
\end{tabular}



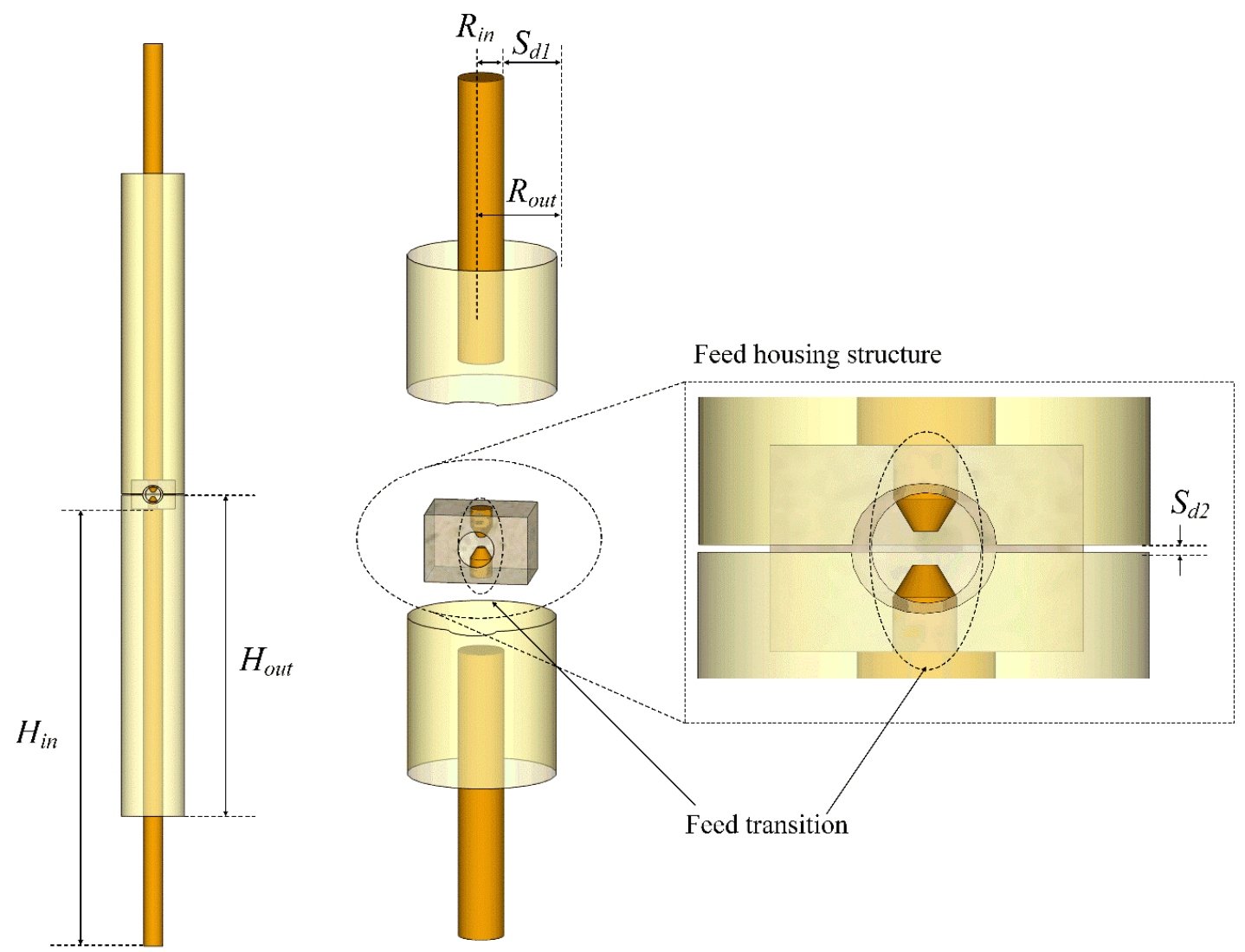

(a)
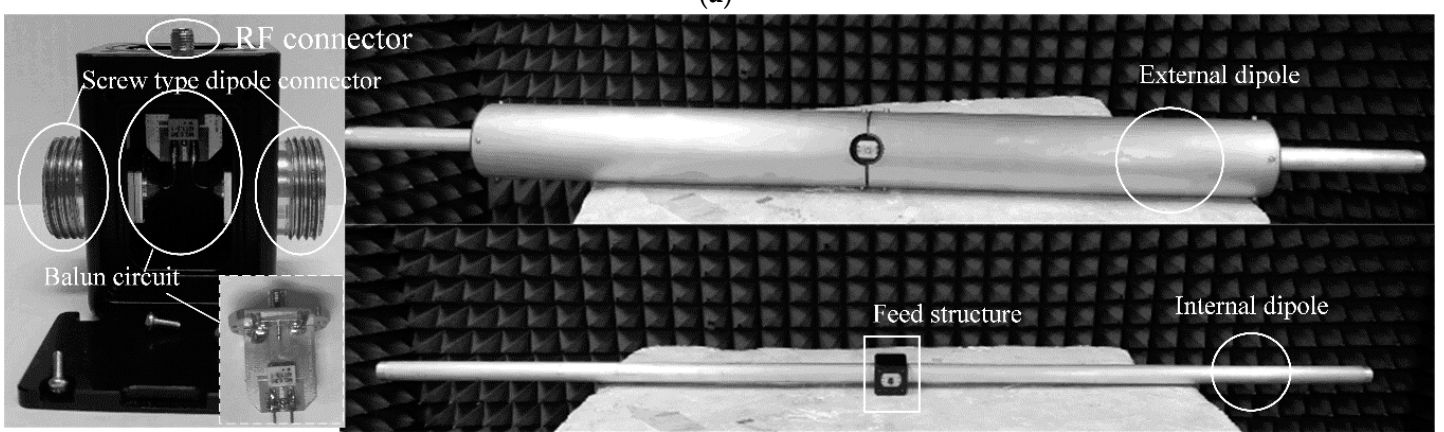

(b)

Figure 3. Geometry of the proposed antenna; (a) designed structure; (b) photographs of the fabricated antenna.

The fabricated antenna was measured at an outdoor test site to investigate the radiation characteristics. Figure $4 \mathrm{a}$ shows the antenna under testing. Figure $4 \mathrm{~b}$ is the outdoor test site, where the test antenna is on the left and the reference antenna is on the right. The distance between the test and reference antennas is $10 \mathrm{~m}$.

Figure 5 shows the VSWR of the proposed coupled-fed dipole antenna and the conventional thin dipole, where the solid and dashed lines represent the measured and simulated results, respectively. In the VSWR simulation, the balun is also included to achieve more accurate results. The FM and T-DMB regions are displayed in gray. There is an additional resonance by the external radiator in the second gray T-DMB region, as shown in Figure $5 \mathrm{~b}$. The proposed antenna shows good matching characteristics in the FM and T-DMB bands, ranging from 88 to $217 \mathrm{MHz}$ (VSWR <2.5). 


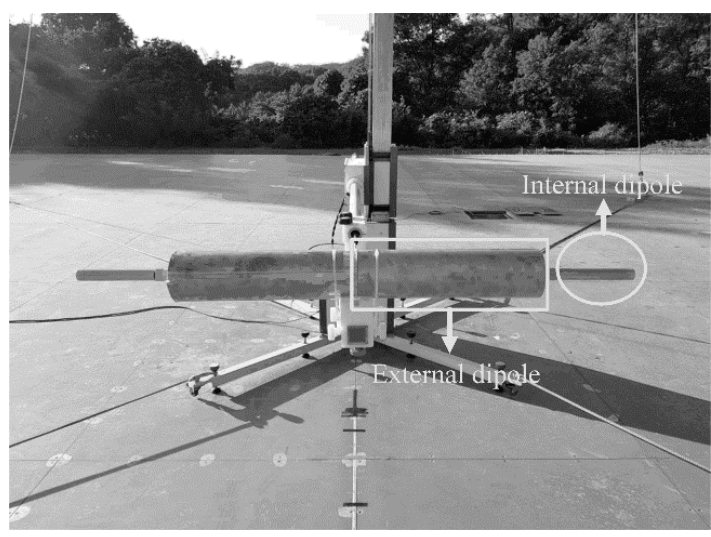

(a)

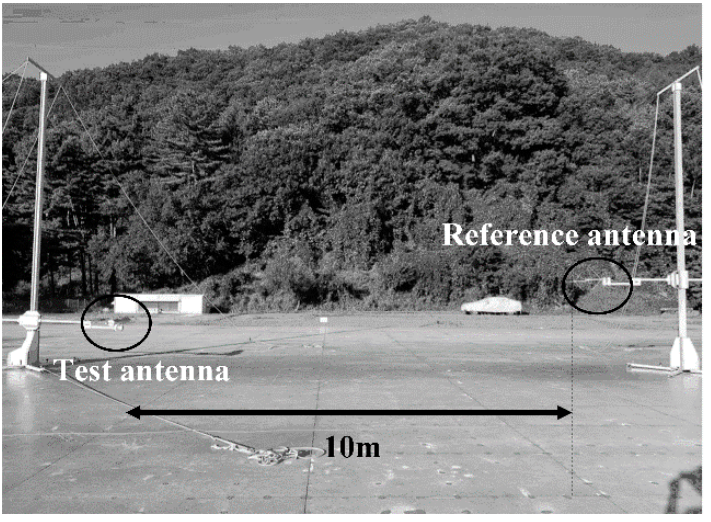

(b)

Figure 4. Outdoor test site: (a) antenna under testing; (b) outdoor test configuration.

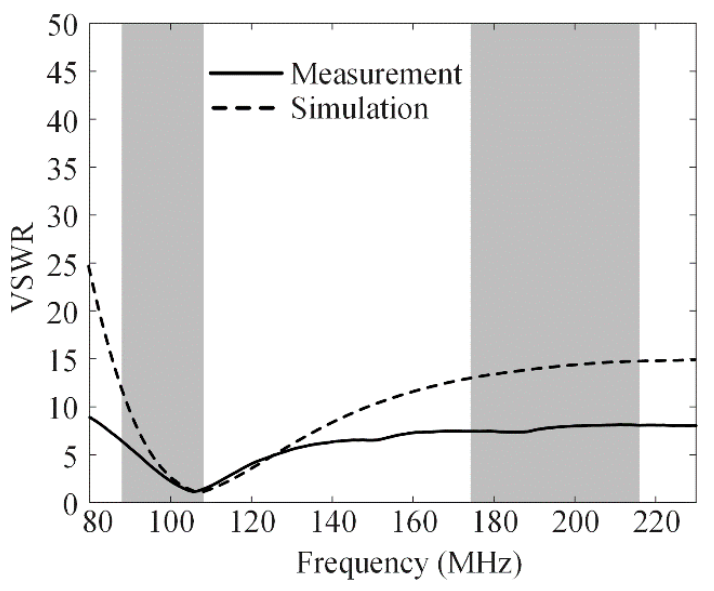

(a)

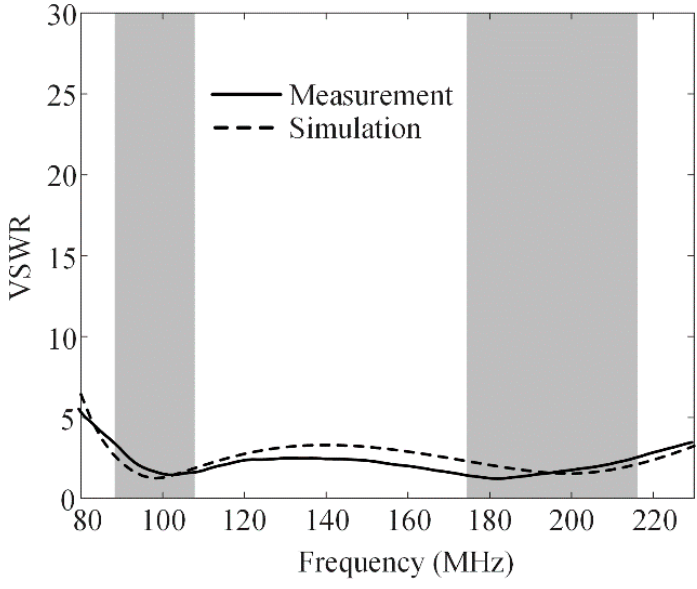

(b)

Figure 5. Impedance matching characteristics of the proposed antenna: (a) conventional thin dipole; (b) proposed antenna.

Figure 6 shows the simulated bore-sight gains compared to the measured data. The results of the proposed antenna are $2 \mathrm{dBi}$ and $2.9 \mathrm{dBi}$ at $100 \mathrm{MHz}$ and $200 \mathrm{MHz}$, while the results of the conventional thin dipole antenna are $0.8 \mathrm{dBi}$ and $-7 \mathrm{dBi}$. The 3-dB gain bandwidth ranges from 83 to $250 \mathrm{MHz}$.

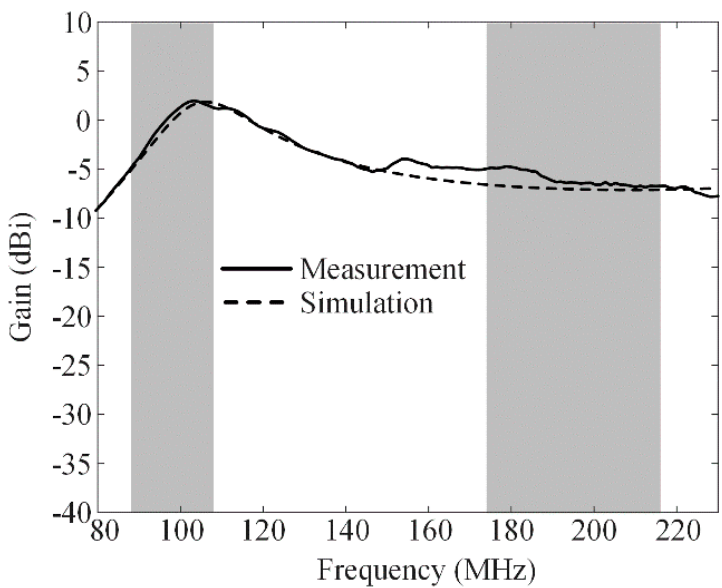

(a)

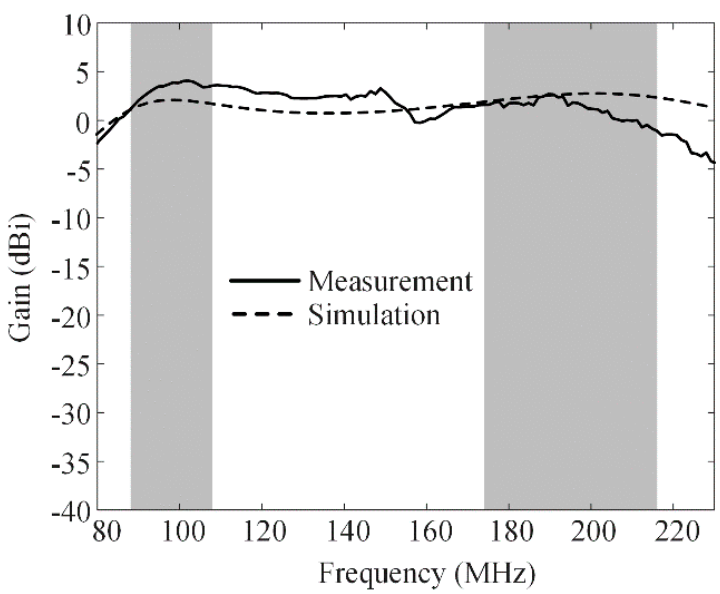

(b)

Figure 6. Bore-sight gains: (a) conventional thin dipole; (b) proposed antenna. 


\section{Location Estimation in the Seoul-Gyunggi Urban Area}

To verify beamforming performance, the proposed coupled-fed dipole element is applied to form an eight-element uniform circular array (UCA), as shown in Figure 7. An array radius of $0.5 \lambda$ from the center to the antenna element is used, and the array is located at a height of $8 \mathrm{~m}$. The detailed parameters for the array are listed in Table 2 . The PCL system typically uses the correlation between the reference and surveillance channels to detect the target. The reference channel is achieved by steering the beam to the base station to pick up the commercial broadcast signals. The surveillance channel is obtained by generating a deep null towards the base station in the radiation pattern to collect echo signals reflected from targets. It follows that properly steered beam and null patterns are critical for PCL system performance.

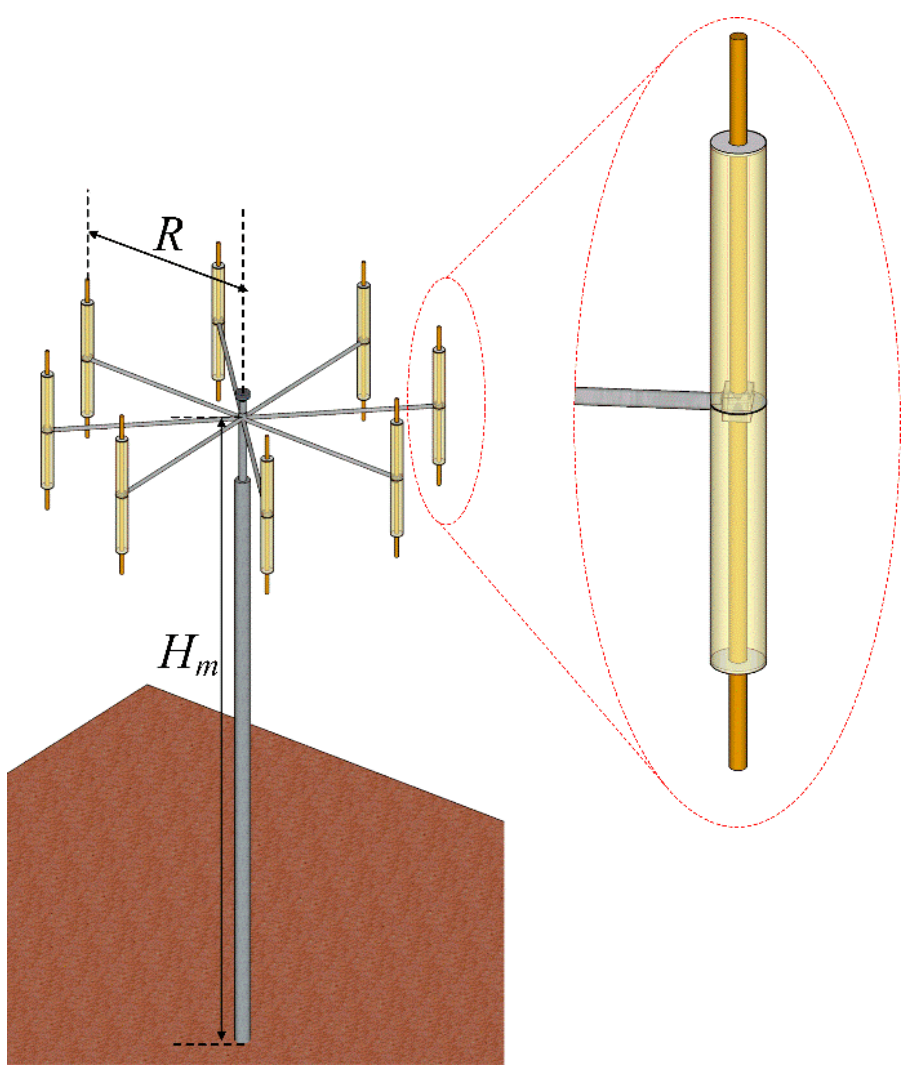

Figure 7. Array configuration of the PCL system.

Table 2. Parameters for array configuration.

\begin{tabular}{cc}
\hline Parameters & Values \\
\hline Number of array & 8 \\
\hline Array type & Uniform circular array \\
\hline Array radius $(R)$ & $0.5 \lambda$ \\
\hline Mast height $\left(H_{m}\right)$ & $8 \mathrm{~m}$ \\
\hline Reference beam & Forming \\
\hline Surveillance beam & Nulling \\
\hline
\end{tabular}

Figure 8 illustrates the reference and surveillance radiation patterns at a T-DMB center frequency of $200 \mathrm{MHz}$. By using the active element pattern (AEP) of each element of the array, the directional and nulling patterns can be obtained. The least-mean-square (LMS) algorithm is used to optimize the feed 
weight for the required steering, which requires a narrow half-power beamwidth (HPBW) and a deep null depth. The average null depth of the surveillance beam is $-37.4 \mathrm{~dB}$, and the average peak to side lobe ratio (PSLR) of the reference beam is $18.6 \mathrm{~dB}$.

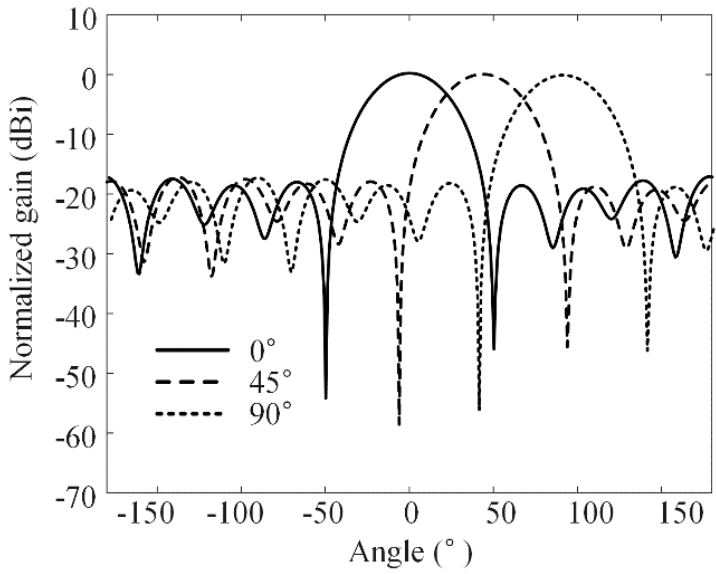

(a)

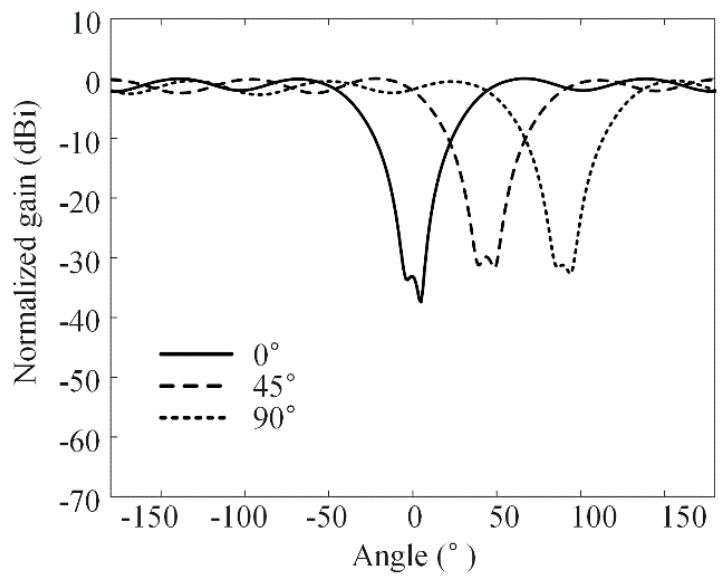

(b)

Figure 8. Optimized radiation patterns: (a) reference channel; (b) surveillance channel.

Equations (1) and (2) are used to derive the cross-correlation in the signals between the reference channel and the surveillance channel $[1,5,8,18,19]$. Since the delay and Doppler frequency of the signal are related to the target's location and velocity, respectively, the ARD map of the target can be driven from the equations.

$$
\begin{aligned}
& \chi\left(t, f_{d}\right)=\int_{-\infty}^{\infty} x_{r}(t) \cdot y_{s}(t) \cdot d t \\
& \chi: \text { Cross correlation } \\
& x_{r}(t): \text { Reference channel signal } \\
& y_{s}(t): \text { Surveillance channel signal } \\
& y_{s}(t)=x_{r}(t-\tau)^{*} e^{j 2 \pi f_{d} t} \\
& \tau: \text { Signal delay } \\
& f_{d}: \text { Doppler frequency }
\end{aligned}
$$

Figure 9 shows the location estimation of the PCL system with the proposed antenna array element. As shown in Figure 9a, the target location is estimated from three elliptical trajectories from one FM and two T-DMB illuminators, which are located in Anseong, Gwanaksan and Gwanggyosan. The symbols, ' $X$ ', ' $\Delta$ ', and 'o' represent the target, the illuminator, and the PCL system, respectively. The distances from the PCL system to the three illuminators are $26.2 \mathrm{~km}$ (Ref.1 in Figure 9a), $38.1 \mathrm{~km}$ (Ref.2 in Figure 9a) and $28.2 \mathrm{~km}$ (Ref.3 in Figure 9a). The blue elliptical trajectory is formed by tracking the position where the sum of two distances (from the PCL system to the target and from the PCL system to the FM station at Ref.2 in Figure 9a) are the same. Similarly, the blue and green elliptical trajectories are formed by the T-DMB stations at Ref.1 and Ref.3 in Figure 9a, respectively. The location where the three elliptical trajectories intersect is supposed as the correct position of the target when three illuminators are used for a single target in the multi-static PCL system. The three ARD maps with one FM and two T-DMB illuminators are shown in Figure 9b. The maximum cross-correlations in the range axis of the ARD map are located at $102.4 \mathrm{~km}, 89.9 \mathrm{~km}$, and $96.2 \mathrm{~km}$. 


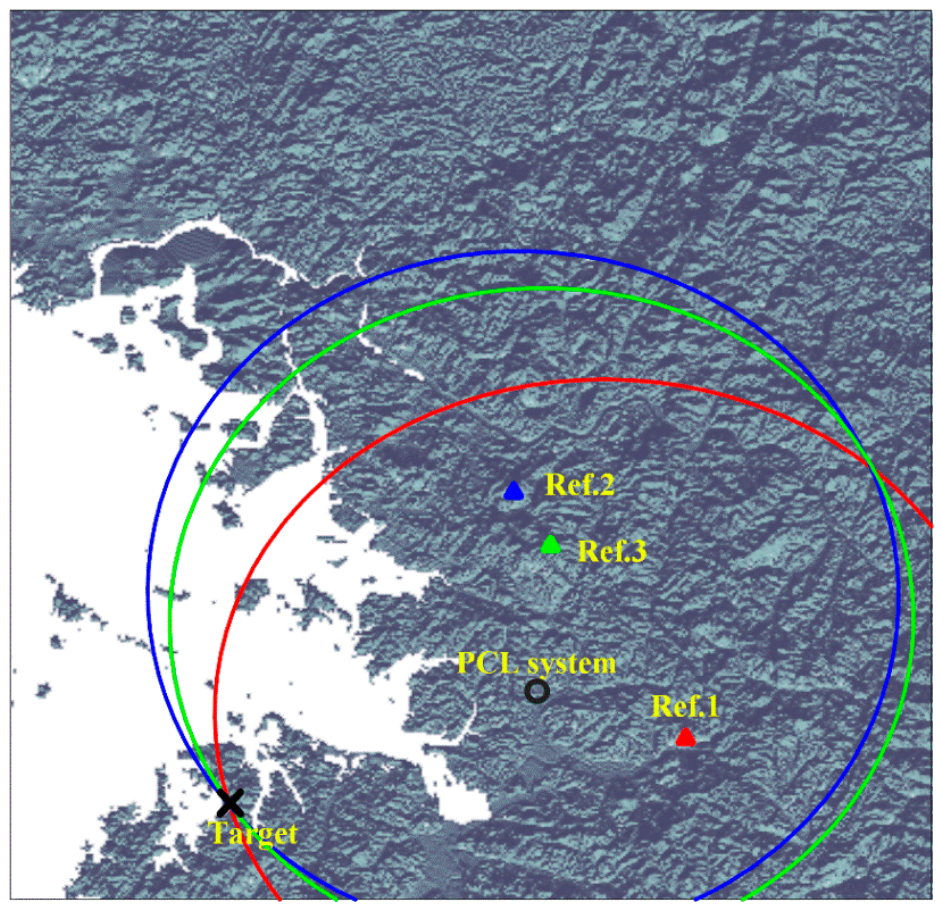

(a)

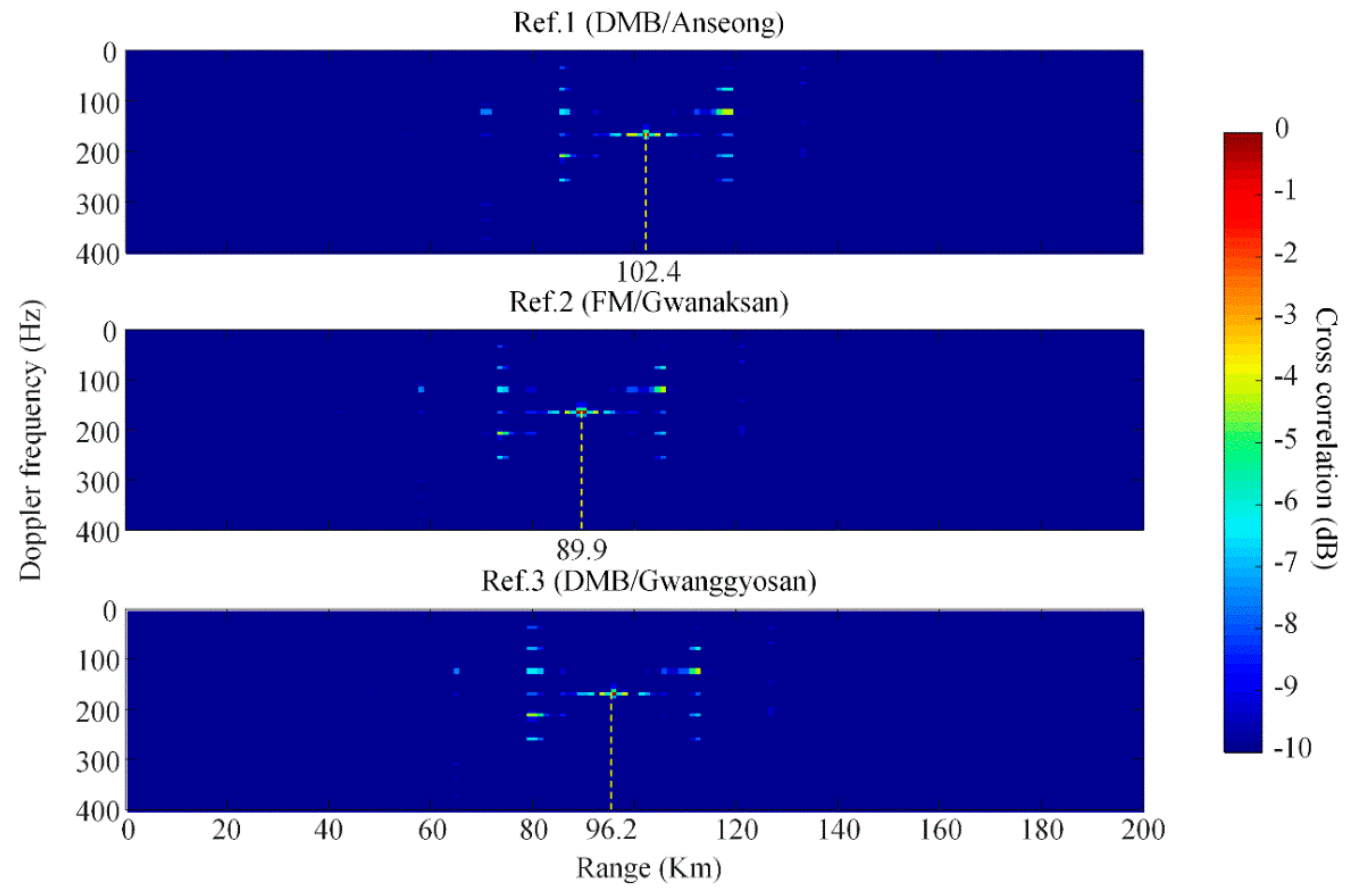

(b)

Figure 9. Location estimation for the target with the proposed antenna array element: (a) location map for three illuminators, the target, and the PCL system; (b) ARD maps from each illuminator.

\section{Conclusions}

The proposed dual-band antenna for PCL systems, comprising internal and external dipoles, can derive the multi-frequency matching characteristics by using an electromagnetically coupled feed mechanism. The simulated VSWR was less than 2.5 from 88 to $217 \mathrm{MHz}$, and the 3-dB gain bandwidth ranged from 83 to $250 \mathrm{MHz}$ in the boresight direction. The proposed dipole antenna element was extended to an eight-element UCA to form the reference and surveillance beams in the T-DMB and FM 
bands. The resulting multi-band performance is suitable for PCL systems by estimating the target location from ARD maps in the Seoul-Gyunggi urban area.

Author Contributions: Conceptualization, H.C. and S.W.; methodology, H.S.; software, S.W. and H.S.; validation, H.C. and S.W.; formal analysis, S.W.; investigation, S.W.; data curation, S.W.; writing-original draft preparation, S.W.; writing-review and editing, H.C.; visualization, S.W.; supervision, H.C.; project administration, H.S.; funding acquisition, H.S. All authors have read and agreed to the published version of the manuscript.

Funding: This work was supported by a grant-in-aid from HANWHA SYSTEMS.

Conflicts of Interest: The authors declare no conflict of interest.

\section{References}

1. Howland, P.E.; Maksimiuk, D.; Reitsma, G. FM radio based bistatic radar. IEE Proc.-Radar Sonar Navig. 2005, 152, 107-115. [CrossRef]

2. Paine, S.; O'Hagan, D.W.; Inggs, M.; Schupbach, C.; Böniger, U. Evaluating the performance of FM-based PCL radar in the presence of jamming. IEEE Trans. Aerosp. Electron. Syst. 2016, 55, 631-643. [CrossRef]

3. Berger, C.; Demissie, B.; Heckenbach, J.; Willett, P.; Zhou, S. Signal processing for passive radar using OFDM waveforms. IEEE J. Sel. Top. Signal Process. 2010, 4, 226-238. [CrossRef]

4. Colone, F.; Langellotti, D.; Lombardo, P. DVB-T Signal ambiguity function control for passive radars. IEEE Trans. Aerosp. Electron. Syst. 2014, 50, 329-347. [CrossRef]

5. Gassier, G.; Chabriel, G.; Barrère, J.; Briolle, F.; Jauffret, C. A unifying approach for disturbance cancellation and target detection in passive radar using OFDM. IEEE Trans. Signal Process. 2016, 64, 5959-5971. [CrossRef]

6. Chabriel, G.; Barrère, J. Adaptive target detection techniques for OFDM-based passive radar exploiting spatial diversity. IEEE Trans. Signal Process. 2017, 65, 5873-5884. [CrossRef]

7. Howland, P.E. Target tracking using television-based bistatic radar. IEE Proc.-Radar Sonar Navig. 1999, 146, 166-174. [CrossRef]

8. Li, Z.; Santi, F.; Pastina, D.; Lombardo, P. Passive radar array with low-power satellite illuminators based on fractional fourier transform. IEEE Sens. J. 2017, 17, 8378-8394. [CrossRef]

9. Santi, F.; Pieralice, F.; Pastina, D. Joint detection and localization of vessels at sea with a GNSS-based multistatic radar. IEEE Trans. Geosci. Remote Sens. 2019, 57, 5894-5913. [CrossRef]

10. Stinco, P.; Greco, M.S.; Gini, F.; Rangaswamy, M. Ambiguity function and Cramér-Rao bounds for universal mobile telecommunications system-based passive coherent location systems. IET Radar Sonar Navig. 2012, 6, 668-678. [CrossRef]

11. Griffiths, H.D.; Baker, C.J. An Introduction to Passive Radar, 1st ed.; Artect House: Norwood, MA, USA, 2017.

12. Wang, S.; Yoo, S.; Park, J.; Shim, H.; Choo, H. Design of a broadband coupled-fed printed dipole antenna as an Array Element for Direction Finding Systems. J. Electromagn. Eng. Sci. 2019, 19, 266-271. [CrossRef]

13. Byun, G.; Hur, J.; Son, S.B.; Choo, H. Design of a coupled feed structure with cavity walls for extremely small anti-jamming arrays. IEEE Access 2019, 7, 17279-17286. [CrossRef]

14. Byun, G.; Kim, S.; Choo, H. Design of a dual-band GPS antenna using a coupled feeding structure for high isolation in a small array. Microw. Opt. Technol. Lett. 2014, 56, 359-361. [CrossRef]

15. Griffiths, H.D. From a different perspective: Principles, practice and potential of bistatic radar. In Proceedings of the International Conference on Radar, Adelaide, Australia, 3-5 September 2003; pp. 1-7.

16. FEKO, Altair. 2019. Available online: http://www.altair.com (accessed on 3 June 2019).

17. Byun, G.; Choo, H.; Ling, H. Optimum placement of DF antenna elements for accurate DOA estimation in a harsh platform environment. IEEE Trans. Antennas Propag. 2013, 61, 4783-4791. [CrossRef]

18. Kim, C.K.; Lee, J.S.; Chae, J.S.; Park, S.O. A modified stripmap SAR processing for vector velocity compensation using the cross-correlation estimation method. J. Electromagn. Eng. Sci. 2019, 19, 159-165. [CrossRef]

19. Yoo, S.; Kim, H.; Byun, G.; Choo, H. Estimation of detection performance for vehicle FMCW radars using EM simulations. J. Electromagn. Eng. Sci. 2019, 19, 13-19. [CrossRef]

(C) 2020 by the authors. Licensee MDPI, Basel, Switzerland. This article is an open access article distributed under the terms and conditions of the Creative Commons Attribution (CC BY) license (http://creativecommons.org/licenses/by/4.0/). 